Environment Conservation Journal 14(1\&2) 27-33, 2013

ISSN 0972-3099 (Print) 2278-5124 (Online)

Abstracted and Indexed

\title{
Influence of UV irradiation on the aflatoxin production capability of Aspergillus spp. isolated from contaminated Arachis hypogea $\mathrm{L}$.
}

\author{
Parul Bishnoi ${ }^{1}$, Harish Chandra $\varpi^{2}$ and S. V. S. Chauhan ${ }^{1}$
}

Received: 15.08.2012

Accepted: 8.01.2013

\begin{abstract}
Aflatoxins are toxic secondary metabolite of fungi such as Aspergillus flavus and A. parasiticus. The fungi occur in a variety of foodstuffs and feed intended for both livestock and human consumption. Aflatoxins produced are potent mutagens and are suspected human carcinogen. During the past two decades several chromatographic and other methods have been developed for identification as well as quantitative determination of aflatoxins in agricultural and food products. An enzyme linked immunosorbant assay (ELISA) was used for the determination of total aflatoxin production in peanut sample and fungal strains after UV irradiation. A. flavus ITCC 1717 and isolated strains were irradiated with different interval of time standard strain and isolated $A$. flavus showed almost similar pattern of reduction, at 12 hr the maximum reduction $98.3 \%$ and $97 \%$ respectively was obtained.
\end{abstract}

Keywords: Aflatoxin, Aspergillus spp., ELISA, UV irradiation

\section{Introduction}

Aflatoxins are secondary metabolites produced by fungal species of genera Aspergillus specifically by Aspergillus flavus and A. parasiticus. It has been reported that out of the known strains of $A$. flavus and A. parasiticus, only about one-half produces toxin. There are 14 known aflatoxins but most of these are metabolites formed endogenously in animals administered by one major toxin, i.e. aflatoxin $B_{1}, B_{2}, G_{1}$ and $G_{2}$. The letters $B$ and $G$ refer to the fluorescent colors blue and green respectively, displayed by the aflatoxins on absorption of long wave UV light and the subscripts 1 and 2 refer to their separation pattern in TLC plates. These toxins are usually found together with various foods and feeds in various proportions; however, aflatoxin $\mathrm{B}_{1}$ is usually predominant and is the most toxic. When $\mathrm{B}_{1}$ and $\mathrm{B}_{2}$ are ingested by dairy cows, a portion of these aflatoxins is hydroxylated and appear in milk in lactating animals as $\mathrm{M}_{1}$ and $\mathrm{M}_{2}$ at the rate of $1.5 \%$ of ingested B aflatoxin (Frobish et al., 1986), which

\section{Author's Address}

${ }^{1}$ School of Life Science, Dr. B.R.Ambedkar University Agra (U.P) India

${ }^{2}$ Department of Biotechnology G.B.Pant Engineering College Ghurdauri, Pauri, Garhwal (Uttarakhand)

E-mail: hreesh5@gmail.com may be found in dairy milk. These metabolites are about $75 \%$ as toxic to ducklings as the parent compounds (Wogan, 1969).Groundnut (Arachis hypogaea L.) occupies an important position in the economy of developing nations. The major groundnut producing countries are India, China and the United States. Groundnut is nutrient dense agricultural product, which is very high in energy due to its high fat and protein content. The carbohydrate content of groundnut is relatively low, being under $30 \%$ of the whole nut. The nut has relatively high content of fiber. It is an industrial crop whose major utilization is a source of oil. The number and type of microbes present on the produce is important in deterioration and numerous molds may be involved, but most common are species of Aspergillus, Penicillium and Fusarium. Aflatoxins present in groundnuts are relatively heat stable and are not eliminated completely by ordinary cooking procedures. A. flavus invades groundnut seeds both at pre-harvest growth stages and at post-harvest drying/curing and storage, producing aflatoxins $B_{1}, B_{2}, G_{1}$ and $G_{2}$.Due to widespread nature of fungi in the ecological system and the production of toxic metabolites by some fungal species, the presence of aflatoxins in foods 
and feeds is a great concern for human and animals health. Although the most effective way to control aflatoxins contamination is to prevent formation of the toxins in field and during storage. Technology does not yet exist for the complete prevention of toxin formation or the removal of aflatoxin from foods and feeds (Chu and Ueno, 1977).

For the past 20 years researchers have studied the immunological method to detect the presence of mold in foods (Shim et al., 2007; Kolosova et al., 2006; Yong and Cousin, 1995; Van der Horst et al., 1992). For aflatoxin detection, a great deal of research has been carried out to search for sensitive, specific and simple method. Among the many methods developed in recent years, immunological methods have been shown to be very promising because of their versatility, sensitivity and specificity. An overall recognition of the potentially wide application of new powerful detection techniques has not only led to simple protocols that allow accurate detection of small amount of aflatoxin in food and feeds but has also generated considerable interest in the preparation of commercial kits for aflatoxin analysis. Recently, kits for the detection and quantitation of aflatoxins have become available from several commercial sources. A number of methods have been investigated in connection with their ability to inactivate aflatoxins in contaminated food and feedstuffs. Chemical used as post harvest treatments causes ecological problems or are potentially harmful to humans, with increasing concern of consumers about residues on fruits and vegetables they have been progressively restricted in most countries. Therefore, safe alternative detoxification or control methods need to be developed (Artes, 1995).Irradiation is a physical method, in which ionizing radiations (e.g. X rays, gamma rays, ultra-violet rays) potential changes may occur in molecules of the irradiated objects and living organisms. Aflatoxins are sensitive to $\mathrm{UV}$ radiation. $\mathrm{AFB}_{1}$ (Aflatoxin $\mathrm{B}_{1}$ ) absorbs UV light at 222, 265 and $362 \mathrm{~nm}$, with maximum absorption occurring at $362 \mathrm{~nm}$, which may lead to the formation of up to 12 photodegradation products (Samarjeeeva et al., 1990). UV energy penetrates the outer cell membrane, passes through the cell body and disrupts its DNA preventing reproduction. The microbicidal activity of the UV light depends on the length of exposure; the longer the exposure the greater the cidal activity. It also depends on the wavelength of UV used. The efficiency of UV-C radiation against a wide variety of microorganisms already has been reported (Abshire and Dunton, 1981; Sommer et al., 1996). The present study was conducted to investigate the presence of aflatoxin in peanut samples collected from local market of New Delhi and efficacy of UV irradiation on aflatoxin detoxification.

\section{Materials and Methods Sampling}

Samples of peanut (Arachis hypogea) were collected from local market of New Delhi, India. All samples were stored in sealed plastic bags and kept at room temperature in dark and dry place. 100 gm sample of peanuts was milled and immediately analyzed for fungal count and total aflatoxin.

\section{Viable plate count of Mycoflora}

Fungal count of peanut was determined by using pour plate method as per IS protocol (IS 5403, 1999) in which $11 \mathrm{gm}$ of finely ground sample were aseptically serially diluted in $99 \mathrm{~mL}$ of pre sterilized $0.85 \%$ of normal saline upto $10^{-6}$ dilution and $1 \mathrm{ml}$ of each dilution was plated on PDA (Potato Dextrose Agar) media. Solidified plates were incubated in inverted position at $28 \pm 1{ }^{\circ} \mathrm{C}$ for 5 days. After five days fungal count was determined using the formula given below. Same dilution was plated on ADM (Aspergillus differential medium, HiMedia ltd) for detection of A. flavus.

$$
\text { Total Fungal count in cfu/gm }=\frac{\Sigma c}{\left(n_{1}+0.1 n_{2}\right) \times d}
$$

Where $\Sigma \mathrm{c}$ is the sum of colonies counted on all the plates.

$\mathrm{n}_{1}$ is the number of plate counted in the first dilution taken.

$\mathrm{n}_{2}$ is the number of plate counted in the second dilution.

$\mathrm{d}$ is the dilution from which the first counts were obtained plate.

Sample preparation and Immunoaffinity clean up $5 \mathrm{~g}$ fine ground powder of peanut were extracted with $25 \mathrm{ml}$ of $70 \%$ aqueous methanol using a laboratory homogenizer and filtered through Whatman No. 1 filter paper. $100 \mu 1$ of each filtrate 
were diluted with $600 \mu 1$ of dilution buffer and $50 \mu 1$ of diluted sample employed to immunoaffinity column (R-Biopharm Ag, Darmstadt, Germany) for cleaning the samples. The basis of the test is the antigen-antibody reaction. The column contains gel suspension to which monoclonal antibodies were attached covalently. The antibodies are specific for the Aflatoxin $B_{1}, B_{2}, G_{1}, G_{2}$ and $M_{1}$. Total aflatoxin content finally eluted with $0.5 \mathrm{ml}$ of HPLC grade methanol and analyzed through ELISA microplate Reader Model 680 (Bio-Rad).

\section{Quantification of Total aflatoxin content}

Quantitative analysis of total aflatoxin was performed by competitive ELISA using Ridascreen total aflatoxin kit, Darmstadt, Germany. 50 $\mu 1$ of standard solution of Aflatoxin and cleaned eluted sample in duplicate added to the wells of microtiter plate. After that $50 \mu$ of peroxidase enzyme conjugate and $50 \mu$ lof mouse monoclonal antiaflatoxin antibodies were added to each well and incubated at room temperature in the dark for 30 minutes. After washing thoroughly with $250 \mu 1$ distilled water three times, $50 \mu 1$ of urea peroxidase (substrate) and $50 \mu 1$ of tetra-methyl-benzidine (chromogen) were added to each well, mixed thoroughly and incubated for 30 minute at room temperature in the dark. Reaction was stopped by adding $100 \mu 11 \mathrm{M}$ sulphuric acid (stop reagent) and the absorbance was measured at $450 \mathrm{~nm}$ using ELISA microplate reader Model 680 (Bio-Rad). A calibration curve was drawn using a wide range of total aflatoxin standards with concentration of $0 \mathrm{ppt}$ to 4050 ppt. (Fig.1).

Fig 1. Standard curve of different concentration of total aflatoxin

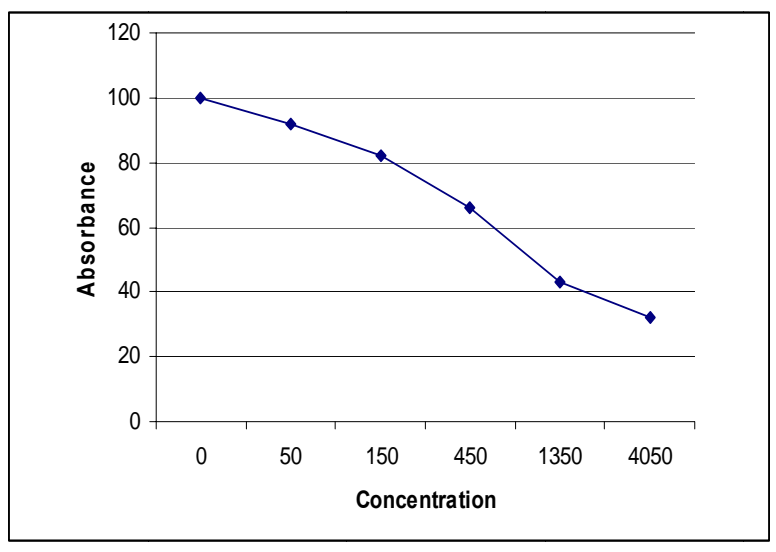

Fungal strains and detection of aflatoxin producing ability of selected strains

The selected strains included A. flavus ITCC-1717 and one strain isolated from peanut kernels have been used for the study. Each isolated strain which gives typical characteristic on ADM (Aspergillus Differentiation Medium) was inoculated at the center of solidified agar medium (PDA) in $9 \mathrm{~cm}$ glass petriplate and incubated at $25^{\circ} \mathrm{C}$. To observe the color change of colony reverse after incubation, dishes was placed upside down and a drop $(0.2 \mathrm{ml})$ of $25 \%$ ammonia solution was put into the lid of Petridish. Immediately after the ammonia solution was put into Petridish, the colony reverse of aflatoxin producing strains become pink and no color change was observed with non-aflatoxin producing strains. The color change was restricted to the colony reverse. The surrounding agar did not show any color change (Saito and Machida, 1999). Detection of Aflatoxin from A. flavus.Yeast malt broth was used as growth media for mycelia growth. $10 \mathrm{ml}$ of reconstitute media in $50 \mathrm{ml}$ centrifuge tube were autoclaved. Each tube was inoculated with a loopful of conidia from all fungal strain cultures and incubated at $25^{\circ} \mathrm{C}$ for 9 days to obtain aflatoxin in detectable yield and the mycelium had fully grown on the broth surface (Davis et al., 1966). The mycelia clumps were harvested by centrifugation $(8,000 \mathrm{x}$ g for $1 \mathrm{~min}$ at $20{ }^{0} \mathrm{C}$ ) and supernatant broth was subjected to aflatoxin detection.For aflatoxin detection, $5 \mathrm{ml}$ of broth was withdrawn into $20 \mathrm{ml}$ centrifuge tube, mixed with $6 \mathrm{ml}$ of chloroform, and vortex for 5 $\mathrm{min}$. Then $5 \mathrm{ml}$ of chloroform was removed to glass tube and flushed with nitrogen to dryness under a hood. The residue was dissolved in $100 \mu$ l of methanol out of which $50 \mu \mathrm{l}$ was used as sample in test procedure of Ridascreen aflatoxin total kit (RBiopharm, Germany).The basis of the test is the antigen-antibody reaction. The wells in the microtiter strips are coated with capture antibodies directed against anti-aflatoxin antibodies. Standards or the sample solutions, aflatoxin-enzyme conjugate and anti-aflatoxin antibodies are added. Free and enzyme conjugate aflatoxins compete for the aflatoxin antibody binding sites (competitive enzyme immunoassay).

At the same time, the aflatoxin-antibodies are also bound by the immobilized capture antibodies. Any 
unbound enzyme conjugate is then removed in a washing step. Enzyme substrate (urea peroxide) and chromogen (tetramethylebenzidine) are added to the wells and incubated. Bound enzyme conjugate converts the colorless chromate into blue product. The addition of the stop solution stops $\mathrm{Ag}-\mathrm{Ab}$ reaction due to which colour changes from blue to yellow. The measurement was made photometrically at $450 \mathrm{~nm}$ by ELISA reader (Bio$\operatorname{Rad} 680$ ).

\section{Effect of UV treatment against A. flavus}

Two strains of the A. flavus were identified for the production of aflatoxin, A. flavus ITCC 1717 and isolates from peanut. The aflatoxigenic strains were exposed with UV rays at different interval of time for the effects on aflatoxin inactivation or production. Fresh cultures of the aflatoxigenic strains on Potato Dextrose media plates were exposed directly to UV-C radiation $(265 \mathrm{~nm}$, germicidal) of 9 watt at $12 \mathrm{~cm}$ distance for different time periods $(2 \mathrm{hr}, 5 \mathrm{hr}, 8 \mathrm{hr}, \& 12 \mathrm{hr})$ in triplicates. A. flavus isolate and A. flavus ITCC 1717 were screened for aflatoxin production using a procedure described by Davis et al (1966). Flasks $(500 \mathrm{ml})$ containing $100 \mathrm{ml}$ sterile YES medium ( $2 \%$ yeast extract and $20 \%$ sucrose) were inoculated with loopful conidium obtained from each isolate and incubated statically for 7-10 day in the dark at room temperature $\left(21^{\circ} \mathrm{C}\right)$. Following incubation, the flask contents were filtered (Whatman Filter No. 1), dried at $70^{\circ} \mathrm{C}$ for $24 \mathrm{hrs}$ in hot air oven and weighed. Individual filtrates (50 $\mu 1)$ were freezedried, dissolved in chloroform (5 $\mathrm{ml}$ ), mixed vigorously, and then quantified for total aflatoxin using an ELISA kit (Ridascreens, RBiopharm AG, Darmstadt, Germany).

\section{Results and Discussion}

The Food and Drug Administration (FDA) has established an "Action Level" of 20 ppb (Part Per Billion) for aflatoxin in peanut in interstate commerce (Table 1).In India the regulatory level are set at $30 \mathrm{ppb}$ for all foods. This is the action at which federal agencies may take action including seizure of the peanut or prohibition of its sale. Elevators do not accept peanut with $20 \mathrm{ppb}$ or more of aflatoxin unless they have a known alternative use. Aflatoxins are very potent compounds that cause variety of human and animal health problems. On rare occasions, livestock can die from ingesting aflatoxin contaminating feed. Most commonly aflatoxin reduces the feed efficiency and reproductivity of livestock. It can suppress the immune system of animals, leading to more frequent occurrence of infectious diseases. In the United State alone, the economic loss from mycotoxin is estimated to be $\$ 932$ million (CAST, 2003). The result of Aflatoxin analysis of peanut samples collected from the local market of New Delhi was presented in Table 2. Viable count of peanut mycoflora varies from $2.9 \times 10^{1}$ to $4.2 \times$ $10^{6} \mathrm{cfu} / \mathrm{gm}$. A viable plate count method for detecting mould contamination is used to determine the mycological quality of foods and agricultural commodities (Liewen and Bullerman, 1992). A high mould count indicates the possibility of aflatoxin contamination. Same dilution was also plated in ADM for the isolation of A. flavus which was merely used for the identification or detection of A. flavus. ADM (Aspergillus differential media) is a selective medium for A. flavus group of fungi which develop characteristic reverse orange color after $42 \mathrm{hrs}$ incubation at $30^{\circ} \mathrm{C}$ (Pitt et al., 1983). Aflatoxin contamination in peanut were determined by using competitive ELISA prior to immunoaffinity column clean up and found that out of 25 samples of peanut tested $19(76 \%)$ samples were found positive for total aflatoxin and out of 19 samples, 13 samples (52\%) were exceeding the maximum limit set by FDA (Table1). A. flavus was isolated in 8 samples and only 1 isolate are able to produce Aflatoxin (Fig. 2). In Gujarat, state of India $42 \%$ of the feed samples was found to be contaminated with aflatoxin (Flounder and Sheila, 1977). A survey of food grains in some village of Mathura District of U.P affected by the floods showed that out of 36 feed samples, 18 were positive for Aflatoxins (Mishra and Singh, 1978). Detection of mould using ELISA and viable plate count, the result shows positive correlation, the ELISA reading correlate the plate count and aflatoxin levels however no absolute pattern, similar type of finding were also reported by Yong and Cousin (2001). The effect of UV radiation on the aflatoxin producing ability of $A$. flavus ITCC 1717 and isolated strain were presented in Fig. 3 and Fig. 4 respectively.Effect of UV radiation on aflatoxin production of A. flavus ITCC 1717 and isolated strains shows almost similar pattern of reduction, at $12 \mathrm{hr}$ the maximum reduction of about 
Table 1. FDA regulatory levels for total aflatoxinsin livestock feeds and human food

\begin{tabular}{|c|c|}
\hline Commodity & $\begin{array}{c}\text { Concentration } \\
\text { ppb }\end{array}$ \\
\hline $\begin{array}{c}\text { All products, except milk, } \\
\text { designated for humans }\end{array}$ & 20 \\
\hline $\begin{array}{c}\text { Corn for immature animals and } \\
\text { dairy cattle }\end{array}$ & 20 \\
\hline $\begin{array}{c}\text { Corn and peanut products for } \\
\text { breeding beef cattle, swine, and } \\
\text { mature poultry }\end{array}$ & 100 \\
\hline $\begin{array}{c}\text { Corn and peanut products for } \\
\text { finishing swine }\end{array}$ & 200 \\
\hline $\begin{array}{c}\text { Corn and peanut products for } \\
\text { finishing beef cattle }\end{array}$ & 300 \\
\hline $\begin{array}{c}\text { Cottonseed meal (as a feed } \\
\text { ingredient) }\end{array}$ & 300 \\
\hline All other feed stuffs & 20 \\
\hline Milk & 0.5 \\
\hline \hline
\end{tabular}

Source: Park and liang [1993] and Park and Njapau [1989]

Fig 2. Aflatoxin producing potential of isolate after exposing to Ammonia vapour. (A) Characteristic pink color indicative of aflatoxin production (Isolate). (B) Negative control (Non Aflatoxin producer)
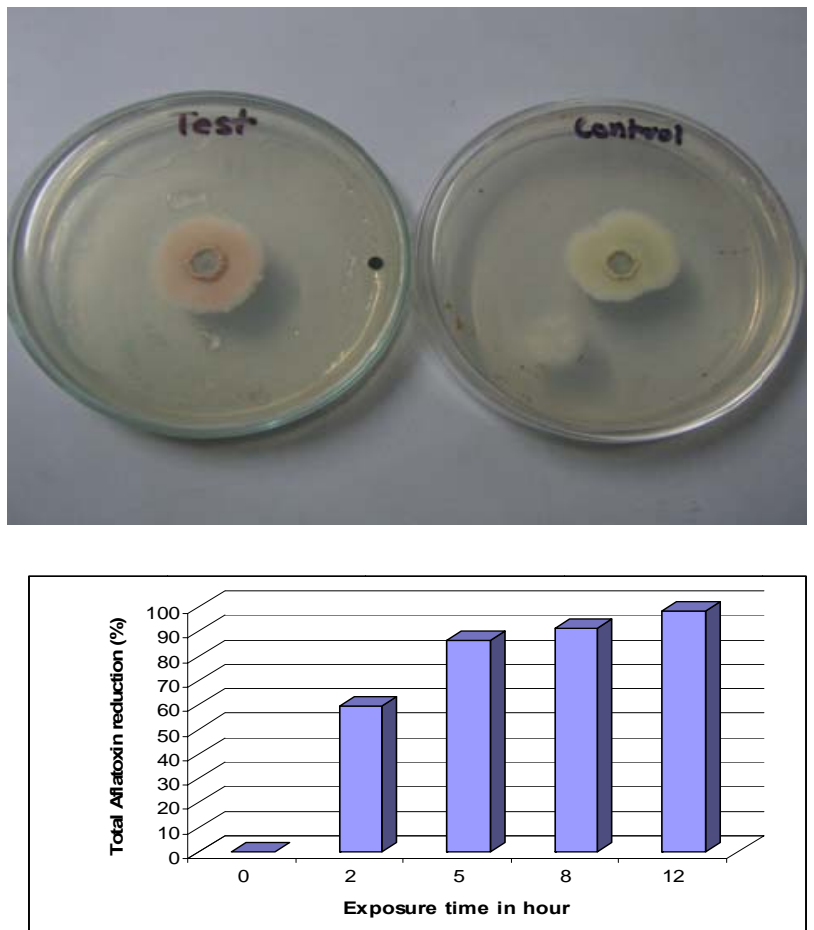

Fig.3. Effect of UV radiation on Aflatoxin producing ability of Isolated $A$. flavus.

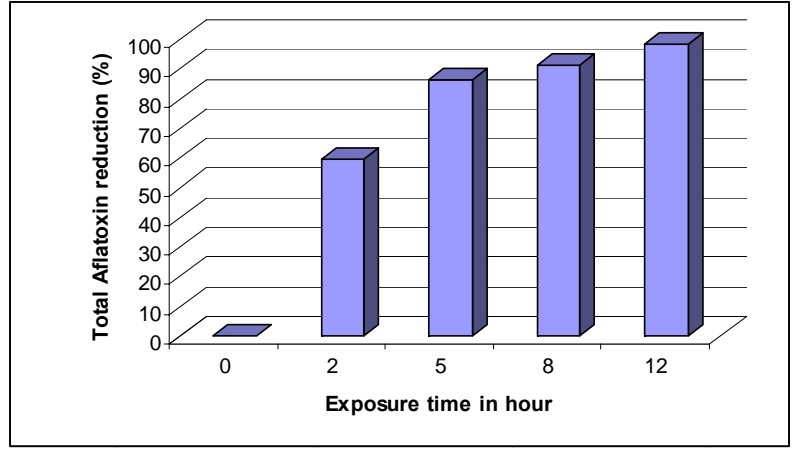

Fig.4. Effect of UV radiation on Aflatoxin producing ability of $A$. flavus ITCC 1717.

$98.3 \%$ and $97 \%$ respectively was obtained. The detoxification of aflatoxin in fungi by UV could be due to two mechanisms: the direct inactivation of $A$. flavus conidia by the radiation or a change in the aflatoxin biosynthesis. UV-C is germicidal and, hence can inactivate fungal spores. The irradiation of fruits with UV-C was effective in the curative control of brown rot (Monilinia fructicola ) and soft rot (Rhizopus stolonifer), and the best results were observed with an exposure time of 10 minutes (Bassetto, 2007). Green et al. (2004), reported that dose of $35 \mathrm{~mJ} / \mathrm{cm}^{2}$ ultraviolet germicidal irradiation can cause $90 \%$ inactivation of $A$. flavus on an agar surface. UV-C radiation was reported to significantly reduce the concentrations of $P$. corylophilum, A. versicolor and Cladosporium spp. UV-C light can significantly reduce the mouldpopulation on shells of eggs after $15 \mathrm{~min}$ exposure (Kuo, 1997). Begum et al. (2009) also studied the effect of ultraviolet irradiation on $A$. flavus, A. niger, Penicillium corylophilum and Eurotium rubrum and found $80-99 \%$ reduction of viable spores for all species except $A$. niger, for which the reduction was only $62 \%$. Treatment of peanut oil with UV light for $2 \mathrm{hrs}$ destroyed 40 $45 \%$ of aflatoxins initially present in the oil (Shantha and Murthy, 1977). Exposure of artificially contaminated milk to UV light inactivated $3.6-100 \%$ of $\mathrm{AFM}_{1}$ in the milk, depending on exposure time $(2-60 \mathrm{~min})$. Also, addition of hydrogen peroxide $(1 \%)$ to the UVirradiated milk (10 min) completely $(100 \%)$ destroyed $\mathrm{AFM}_{1}$ (Yousef and Marth, 1985). The photodegradation products were less toxic to chick embryo than the parent toxins (Andrello et al., 
1967). UV radiation (30 $\mathrm{min}$ ) of dried figs Enterica Ser. Enteritidis was also reported by de artificially contaminated with AF-B ${ }_{1}(250 \mu \mathrm{g} / \mathrm{Kg})$ Souza and Fernandez (2011). UV radiation does not reduced the aflatoxin level by $45.7 \%$ (Altug et al., require heat or chemical and inexpensive. It is more 1990). Chun et al. (2010) evaluated the inactivation advantageous than other existing sanitation method. of food borne pathogens on chicken breasts by FDA already approved the use of UV-C different dose UV-C radiation and found that at 5 (wavelength of 220-300 nm with $90 \%$ of emission $\mathrm{kJ} / \mathrm{m}^{2}$ reduce the microbial population. Reduction in at $253.7 \mathrm{~nm}$ ) on food products to control count of inoculated Salmonella enterica subsp. microorganism (Park and Liang, 1993).

Table2. Total aflatoxin and fungal count in Peanut sample

\begin{tabular}{|c|c|c|c|}
\hline Sample No. & $\begin{array}{r}\text { Fungal count } \\
(\mathbf{c f u} / \mathbf{g m})\end{array}$ & TAF (ppb) & Growth on ADM \\
\hline 1 & $2.8 \times 10^{5}$ & 141 & + \\
\hline 2 & $1.4 \times 10^{4}$ & 46 & + \\
\hline 3 & $2.4 \times 10^{2}$ & 27 & + \\
\hline 4 & $2.9 \times 10^{1}$ & 16 & - \\
\hline 5 & $4.6 \times 10^{2}$ & 2 & - \\
\hline 6 & $9.6 \times 10^{4}$ & 38 & + \\
\hline 7 & $1.2 \times 10^{3}$ & 28 & + \\
\hline 8 & $2.5 \times 10^{5}$ & 144 & + \\
\hline 9 & $3.8 \times 10^{2}$ & ND & - \\
\hline 10 & $4.2 \times 10^{6}$ & 126 & + \\
\hline 11 & $9.2 \times 10^{2}$ & 34 & + \\
\hline 12 & $1.8 \times 10^{2}$ & 46 & + \\
\hline 13 & $4.4 \times 10^{3}$ & 54 & + \\
\hline 14 & $5.2 \times 10^{2}$ & ND & + \\
\hline 15 & $8.0 \times 10^{2}$ & ND & + \\
\hline 16 & $6.2 \times 10^{2}$ & ND & - \\
\hline 17 & $2.0 \times 10^{4}$ & 86 & + \\
\hline 18 & $1.1 \times 10^{2}$ & ND & - \\
\hline 19 & $2.0 \times 10^{2}$ & 24 & + \\
\hline 20 & $1.4 \times 10^{3}$ & 14 & - \\
\hline 21 & $1.6 \times 10^{2}$ & 25 & + \\
\hline 22 & $3.1 \times 10^{2}$ & 75 & + \\
\hline 23 & $1.9 \times 10^{4}$ & 19 & + \\
\hline 24 & $2.7 \times 10^{2}$ & 28 & + \\
\hline 25 & $2.3 \times 10^{2}$ & ND & - \\
\hline
\end{tabular}

TAF- Total Aflatoxin, ND- Not Detected, + sign indicate growth which shows typical characteristics of A. flavus

\section{References}

Abshire, R.L. and Dunton, H., 1981.Resistance of selected strains of Pseudomonas aeruginosa to low-intensity ultraviolet radiation. Appl. Environ. Microbiol., 41:1419-1423.

Altug, T., Yousef, A.E. and Marth, E.H., 1990. Degradation of Aflatoxin $B_{1}$ in dried figs by sodium bisulfite with or without heat, Ultraviolet energy or hydrogen peroxide. J. Food Prot., 53:581-582.

Andrello, P.J., Beckwith, A.C. and Eppley, R.M., 1967. Photochemical changes of Aflatoxin $\mathrm{B}_{1}$. J. Assoc. Off. Anal. Chem., 50:346-350. 
Artes, F., 1995. Innovations in physical treatments for preserving post harvest quality of fruits and vegetables; Heat Pretreatments. Revista Espanola Ciencia Tecnologia Alimentos, 35(1): 45-64.

Bassetto, E., Amorim, L., Benato, E.A., Gonçalves, F.P. and Lourenço, S.A., 2007. Effect of UV-C irradiation on postharvest control of brown rot (Monilinia fructicola) and soft rot (Rhizopus stolonifer) of peaches. Fitopatol. Bras., 32:393-399.

Begum, M., Hocking, A.D. and Miskelly, D., 2009. Inactivation of food spoilage fungi by ultra violet (UVC) irradiation. Inter. J.Food Microbiol., 129: 74-77.

CAST.2003. Mycotoxins: Risks in plant, animal, and human systems Ames Iowa USA Council for Agricultural Science and Technology: 199.

Chu, F.S. and Ueno, I., 1977 Production of Antibody against Aflatoxin $B_{1}$. J. Appl. Environ. Microbial. 33: 1125-1128.

Chun, H.H., Kim, J.Y., Lee, B.D., Yu, D.J. and Son, K.B., 2010. Food Control, 21:276-280.

Davis, N.D., Diener, U. and Eldridge, D., 1966. Production of aflatoxin B1 and G1 by Aspergillus flavus in a semisynthetic medium. Appl. Microbiol., 14: 378-380.

De Souza, P.M. and Fernandez, A., 2011. Effect of UV-C irradiation on physiochemical quality attributes and Salmonella eneritidis inactivation in liquid egg product. Food Control, 22: 1385-1392.

Flounder, A.B. and Sheila, P.C., 1977. Qualitative studies on the aflatoxins in cattle feed of Gujarat State. Gujarat Agricul. Uni.Res. J., 3:78-81.

Frobish, R.A., Bradley, B.D., Wagner, D.D., Long-Bradley, P.E. and Hairsten, H., 1986. Aflatoxin residue in milk of dairy cows after ingestion of naturally contaminated grains. $\boldsymbol{J}$ Food Protect, 49:781-785.

Green, C.F., Scarpino, P.V., Jensen, P., Jensen, N.J. and Gibbs, S.G., 2004. Disinfection of selected Aspergillus spp. using ultraviolet germicidal irradiation. Canadian J. Microbiol., 50: 221-224.

IS 5403: 1999. Methods for Yeast and mould count of foodstuffs and poultry and animal feed.

Kolosova, A.Y., Shim, W.B., Yang, Z.Y., Eremin, S.A. and Chung, D.H., 2006. Direct competitive ELISA based on a monoclonal antibody for detection of aflatoxin $\mathrm{B}_{1}$, stabilization of ELISA kit components and application to grain samples. Annal. Bioannal.Chem. 384 (1):286-294.

Kuo, F., Carey, J.B. and Ricke, S.C., 1997.UV irradiation of shell eggs: effect on populations of aerobes, molds and inoculated Salmonella typhimurium. J. Food Prot., 60: 639-643.
Liewen, M.B. and Bullerman, L.B., 1992. Toxigenic fungi and fungal toxins In: Vanderzant, C., Splittstoesser, D.F. (Eds) Compendium of methods for the microbiological examination of Foods $3^{\text {rd }}$ Edn American Public Health Association Washington DC, pp 811-819.

Mishra, R.S. and Singh, R.S., 1978. Aflatoxin contamination of grains in flooded area of Mathura, Uttar Pradesh. Current Sci., 47:396-399.

Park, D.L. and Liang, B., 1993. Perspectives on aflatoxin control for human food and animal feed. Trends Food Sci.Technol. 4: 334-342.

Park, D. L. and Njapau, H., 1989. Contamination issues and padding. J. Am. Oil Chem. Soc., 66:1402-1405.

Pitt, J.I., Hocking, A.D. and Glenn. D.R., 1983. An improved medium for the detection of Aspergillus flavus and Aspergillus parasiticus. J Appl. Bacteriol., 54:109-114.

Saito, M. and Machida, S., 1999. A rapid identification method for aflatoxin-producing strains of Aspergillus flavus and $A$. parasiticus by Ammonia vapor. Mycoscience, 40:205-208.

Samarjeeeva, U., Sen, A.C., Cohen, M.D. and Wei, C.I., 1990. Detoxification of Aflatoxin in foods and feed by physical and chemical methods. J Food Prot, 53:489-501.

Shantha, T. and Murthy, V.S., 1977. Photodestruction of aflatoxin in groundnut oil. Indian J Tech, 15:453-454.

Shim, W.B., Yang, Z.Y., Kim, J.Y., Kang, S.J., Woo, G.J., Chung, Y.C., Sergei, A.E. and Chung, D.H., 2007. Development of Immunochromatography strip-test using nanocolloidal gold antibody probe for the rapid detection of aflatoxin $\mathrm{B}_{1}$ in grain and feed samples. J. Microbiol. Biotech., 17(10): 1629-1637.

Sommer, R., Haider, T., Cabaj, A., Heidenreich, E. and Kundi, M.1996. Increased inactivation of Saccharomyces cerevisiae by protraction of UV irradiation. Appl. Environ. Microbiol., 62:1977-1983.

Van der Horst, M., Samson, R.A. and Karman, H., 1992. Comparison of two commercial kits to detect moulds by latex agglutination In: Samson RA, Hocking AD, Pitt JI, King, AD $\mathrm{Jr}$ (Eds) Modern Methods in Food Mycology. Elsevier, Amsterdam, pp 241-245.

Wogan, G.N., 1969. In Aflatoxins", Goldblatt, L.A. (Ed) Academic Bess, New York, pp 152-157.

Yong, R.K. and Cousin, M.A., 1995. Nonspecific enzyme-linked immunosorbent assay for moulds in foods. J Food Sci., 60: 1357-1363.

Yong, R.K. and Cousin, M.A., 2001. Detection of moulds producing aflatoxin in maize and peanut by an immunoassay. Int. J. Food Microbiol., 65 (1-2): 27-38.

Yousef, A.E. and Marth, E.H., 1985. Degradation of Aflatoxin M1 in Milk by UV Energy. J Food Prot, 48 (8): 697-698. 